\title{
tö-ra
}

to = rea

Jurnal Hukum: HUKUM UNTUK MENGATUR DAN MELINDUNGI MASYARAKAT

Fakultas Hukum Universitas Kristen Indonesia

p-ISSN: 2442-8019 and e-ISSN 2620-9837

Volume 7 Nomor 1 April $2021 \mathrm{Hal}$ 199-207

Submit: 07/02/2021, diterima 30/03/2021, diterbitkan 29/04/2021

\section{SISTEM HUKUM PIDANA TERHADAP CEK/BILYET GIRO KOSONG}

Toga Lamhot Sinaga

Magister Ilmu Hukum, Universitas Kristen Indonesia, Jakarta, Indonesia

togasinaga@yahoo.com

\begin{abstract}
This writing scientific paper discusses about the form legal protection to blank cheque or bilyet giro givers. It begins with receivable debt agreement and bases on rules and regulation Number 17 in 1964 which has been revoked in rules and regulation 1 in 1971, which was originally criminal act, the cause of its recocation is society concern in running businesses with cheque ang giro which considerably slowed dwon the ecomomic traffic. Since then, rules and regulation number 1 in 1971 were declared so that it was no longer criminal act, and investigators could bring it to criminal affairs stated in article. From the mentioned problem above, the writer is trying to make an analysis which sets the blank ceque and biyet giro givers protection using legal system of Lawrence M,Friedman.
\end{abstract}

Keywords : cheque, bilyet, system of law 


\section{PENDAHULUAN}

Berbagai masalah yang berkembang di masyarakat pada umumnya ketidak tahuan mengenai akibat suatu perbuatan hukum yang dilakukan, untuk meyakinkan satu atau lebih orang untuk mendapatkan keuntungan bagi dirinya ataupun orang lain. Permasalahan pelanggaran perbuatan hukum banyak ditemukan dalam berbisnis dengan pihak-pihak yang dikenal baik dan yang tidak dikenal, dan oleh karenanya dalam menjalankan bisnis tersebut maka dibuatlah suatu perjanjian ataupun berkontrak yang satu dengan yang lain sesuai dengan Pasal 1320 KUH Perdata. ${ }^{1}$ (Kesepakatan yang mengikat kedua belah pihak, Kecakapan dalam membuat suatu perikatan, Suatu pokok persoalan tertentu dan Suatu sebab yang tidak terlarang)

Di dalam menjalankan bisnis tersebut diperlukan suatu alat bayar berupa Bilyet Giro (BG) atau Cek untuk menjalankan dan memperlancar bisnis. Cek/Giro adalah perintah pembayaran (kepada Bank) dari orang yang membawanya atau

orang yang namanya tersebut dalam cek, tersebut dalam cek sejumlah uang yang tertera diatasnya. ${ }^{2}$

Dalam bagian tertentu Cek dan Giro mempunyai persamaan, akan tetepi ada halhal yang membedakan secara prinsip. Surat Cek memiliki nilai ekonomis sebagai alat pemberian tunai atau dapat diuangkan secara langsung oleh siapun juga. Sedangkan Giro tidak dapat diuangkan secara langsung hanya dapt dipindah bukukan.

Dalam perjalanan bisnis yang memakai alat pembayaran berupa Cek dan Giro sering terjadi Cek dan Giro yang diberikan tidak ada dananya dalam rekening pemberi Cek dan Giro tersebut yang sering disebut Cek/Giro kosong. Dan hal tersebut dilaporkan ke pihak Kepolisian dengan dugaan tindak pidana penipuan sebagaiman dimaksud dalam pasal 378 KUHP yang berbunyi :

"Barang siapa dengan maksud untuk menguntungkam diri sendiri atau orang lain secara melawan hukum dengan memakai nama palsu atau martabat palsu, dengan tipu muslihat ataupun rangkaian kebohongan, menggerakkan orang lain untuk menyerahkan barang sesuatu kepadanya, atau supaya memberi utang maupun menghapus piutang, diancam karena penipuan, dengan pidana penjara paling lama empat tahun"

Berdasarkan pengaturan UU No, 17 Tahun 1964 tentang Larangan Penarikan Cek kosong ("UU Cek Kosong), yang secara khusus menyatakan bahwa tindak pidana penarikan cek kosong adalah kejahatan. Yang dipidana dengan mati, pidana seumur hidup atau pidana penjara sementara selama-lamanya dua puluh tahun dan pidana denda sebanyak-banyaknya empat kali jumlah yang ditulis dalam cek kosong yang

\footnotetext{
${ }^{1}$ Tim Redaksi BIP, Bhuana Ilmu Pelopor, IKAPI: 246?GKI/04; hlm 364.

2 Farida Hasyim,Hukum Dagang, Sinar Grafika Lampung 2009; hal 249 
bersangkutan. ${ }^{3}$ Namun UU tersebut telah dicabut oleh pemerintah dan tertuang dalam Peraturan Pemerintah Pengganti Undang-Undang Nomor 1 Tahun 1971. yang mengartikan bukan tindak pidana lagi. Perpu Nomor 1 Tahun 1971 pengganti UU Nomor 17 Tahin 1964 tentang pencabutan Larangan Cek Kosong, Akan tetapi perihal tersebut dapat kemungkinan dituntutnya mengenai cek kosong jika permasalahan itu memenuhi unsur-unsur tindak pidana lain, misalnya dalam pidana Pasal 378 KUHP. ${ }^{54}$

Pembahasan kasus dalam jurnal ini yang telah diputus oleh Pengadilan Jakarta Selatan dalam perkara Nomor : 335/Pid.B/2016/PN.JKT.SEL tertanggal 16 Juni 2016 antara "ALI (terdakwa) dengan Kaliong".

yang pada awalnya tahun 2013 Ali meminjam uang pada Kaliong dan dalam perjalanannya Ali beberapa kali sudah/telah melakukan pembayaran beserta bunga yang mereka sepakati, baik melakukan transfer tunaidan memakai Cek/Bilyet Giro.

Namun dikarenakan situasi dan kondisi keuangan Ali yang kurang menguntungkan, Ali memberikan beberapa cek/Bilyet Giro untuk sebagai alat bayar. Dan dalam situasi yang semakin buruk dalam keuangannya ada beberapa cek/Giro yang diberikan pada Kaliong tidak ada dana yang tersedia pada rekening Ali alias kosong. Dalam hal ini Kaliong melaporkan Ali pada Mabes Polri yang disangkakan melakukan tindak Pidana penipuan pada Pasal 378 KUHP dan hingga sampai tingkat ke pengadilan Jakarta Selatan dan dalam Putusan perkara Nomor : 335/Pid.B/2016/PN.JKT.SEL tersebut Ali di Hukum Penjara 3 (tiga) tahun.

\section{Rumusan Masalah}

- Bagaimana Sebaiknya dalam mengatur Cek/Bilyat Giro pada lus Constituendum.

\section{Tujuan Penulisan :}

Memberikan gambaran/pandangan hukum apa yang seharusnya dalam mengatur penggunaan Cek/Bilyat Giro pada lus Contituendum (hukum pada saat yang akan datang) sehingga memperlancar kegiatan usaha khususnya lintas perekonomian.

\section{Pembahasan :}

Dengan memakai teori Lawrence W. Friedman tentang penegakan hukum agar lebih efektif harus tergantung pada sistem hukum yaitu sistem struktur hukum, substansi hukum, dan budaya hukum.

\footnotetext{
${ }^{3}$ Undang-undang Republik Indonesia nomor 17 Tahun 1964 tentang larangan penarikan cek kosong

${ }^{4}$ Undang-undang Republik Indonesia nomor 1 Tahun 1971 tentang pencabutan Larangan penarikan Cek kosong nomor 17 Tahun 1964
} 


\section{SISTEM HUKUM}

Bila melihat kasus tersebut diatas dan dibandingkan dengan perpu Nomor 1 Tahun 1971 pengganti UU Nomor 17 Tahun 1964 tentang pencabutan Larangan Cek Kosong

Menurut Lawrence W. Friedman, menyatakan bahwa efektif atau tidaknya penegakan hukum adalah tergantung sistem hukum yang mencakup tiga sub sistem yaitu sistem struktur hukum, substansi hukum, dan budaya hukum.dan dalam uraian sub sistem tersbut sebagai berikut $:^{5}$

1 Struktur Hukum, Secara lebih sederhana struktur hukum tersebut berkaitan dengan kelembagaan dan kinerja kelembagaan beserta dengan aparatnya dalam melaksanakan dan dalam menegakkan hukum yang termasuk di dalamnya ada disain sebagaimana hukum itu dilaksanakan atau ditegakkan sesuai aturan formalnya atau menyangkut kinerja hukum. Dan yang merupakan institusi penegak hukum seperti kepolisian, kejaksaan, Pengadilan dan lembaga pemasyarakatan dan Lawrence M. Fredman menyatakan :

"The structure of a system is its skeletal framework; it is the permanent shape, the institutional body of the system, the though rigid bones that

keep the process flowing within bounds, We describe the structure of a judicial sistem when we talk about the number of judges, the jurisdiction the court, haw higher courts are stacked on top of lower courts, what person are att ached to various courts and what their roles consist of ${ }^{6}$ ("struktur sebagai sebuah sistem bentuk yang permanen, sistem kelembagaan, meskipun akan kaku dalam sebuah proses yang terbatas. Kita menguraikan suatu sistem struktur suatu tentang pengadilan, pengadilan tinggi adalah lembaga diatasnya pengadilan rendah, orangnya yang terikat dengan bermacam pengadilan dan apa peranan mereka")

Bila melihat Kitab Undang-Undang Hukum Acara Pidana (KUHAP) Pasal 7 kewenangan Penyidik, Kewenangan Penuntut Umumn sesuai KUHAP nomor 8 Tahun 1981 Pasal 14 dan Kewenangan Pengadilan untuk mengadili sesuai Undang- Undang Hukum Acara Pidana Nomor 8 Tahun 1981

Melihat kewenangan penyidik diatas penulis melihat kelemahan penyidik dalam Penegakan hukum Cek dan Giro terkait pelaksanaan hukum, penulis melihat dalam kasus tersebut terdapat kelemahan-kelemahan dalam praktik di lapangan, yaitu kurang trampilnya aparat penegak dalam hal ini penyidik hukum maupun kurang pahamannya masyarakat tentang peraturan-peraturan hukum berkaitan dengan Cek dan Giro, bahwa

\footnotetext{
${ }^{5}$ Kurniawan Triwibowo, Hukum dan Keadilan-Peradilan yang tidak Kunjung Adil, Papas Sinar Sinanti, Jakarta,2020; hlm 30

${ }^{6}$ Lawrence M.Friedman, Sistem Hukum Persepektif Ilmu Sosial, Diterjemahkan oleh M.Khozim, Nusamedia $2011 ;$ hlm 14
} 
Cek dan Giro adalah produk dari perbankan yang digunakan sebagai alat bayar dalam mempermudah transaksi atau lalu lintas berbisnis dalam kemajuan perekonomian dalam masyarakat. Aparat penegak hukum masih kurang memahami tentang adanya peraturan Undang-undang Republik Indonesia nomor 1 Tahun 1971 tentang pencabutan Larangan penarikan Cek kosong nomor 17 Tahun 1964, dan penulis menduga adanya "Atensi dari pihak-pihak yang mempunyai kekuatan politik". Ini mengakibatkan kualitas penegakan hukum menjadi kurang memuaskan yang berdampak pada masyarakat yang lemah pada umumnya. Melihat wewenang ketiga struktur diatas maka sistem hukum yang disampaikan oleh Lawrence $\mathrm{M}$. Friedman pada tiga komponen tersebut diatas dapat diartikan bahwa ketiga komponen tersebut saling terkait dan saling mempengaruhi.

Sistem hukum tidak mungkin akan berjalan dengan baik apabila tidak ditopang oleh aparat yang punya perofesionalitas dan integritas

Penulis ingin menyampaikan dari kewenangan Penuntut umum perlu adanya pembaharuan untuk kedepan dimana Penuntut umum yang seharusnya setelah menerima pelimpahan berkas tersangka dari penyidik Polri (sebelum P21) Penuntut umum diberikan kewenangan tambahan berupa wewenang nntuk memeriksa tersangka pada tingkat penuntut umum, hal ini untuk menghindari adanya BAP yang diperiksa penyidik ada yang terlewatkan atau "dihilangkan" oleh penyidik. Termasuk dengan hakim yang akan menyidangkan untuk dapat menengahi atau konsolidasi/koordinasi bahwa adanya Peratura-peraturan yang belum diketahui oleh kesemua lembaga terkait.

Kebijakan atas penambahan dan konsolidasi dan koordinasi bertujuan supaya subsistem struktur hukum dapat terlaksana/terintegrasi dengan baik agar tercapainya sinkronisasi antar penegak hukum, penyidik, penuntut umum dan pengadilan dalam hal ini hakim sehingga kinerjanya untuk penegakkan hukum lebih efektif. Pada prinsipnya fungsi hukum adalah 'sarana pembaharuan masyarakat' ${ }^{7}$

2 Substansi Hukum: Adalah aturan, norma dan pola perilaku manusia yang berada di dalam sistem itu dan tidak hanya sebatas pada hukum yang tertulis, akan tetapi juga hukum yang hidup dan berlaku di dalam masyarakat, ${ }^{8}$ Dan substansi ini menyangkut norma, aturan dan pola keprilakuan manusia dalam

sistem tersebut, dan juga termasuk etika dan asas, serta putusan pengadilan. Dengan demikian komponen substansi hukumnya adalah keseluruhan aturanaturan hukum, baik yang tertulis dan juga yang tidak tertulis, serta putusan pengadilan yang berpedoman pada pemerintah dan masyarakat, asas-asas hukum yang tidak tertulis maupun yang tertulis bahwa dengan sendirinya harus berakar

\footnotetext{
${ }^{7}$ Mochtar Kusumaatmadja Hukum, Masyarakat, dan Pembinaan Hukum Nasional, Bandung 1995.BinaCipta, Bandung, 1995: hlm. 13.

${ }^{8}$ Kurniawan Triwibowo, Hukum dan Keadilan-Peradilan yang tidak Kunjung Adil, Papas Sinar Sinanti, Jakarta,2020;hlm 30.
} 
pada falsafah bangsa Indonesia yaitu Pancasila yang menjadi sebagai pedoaman, penuntun pemandu bagi penerapan dan pembentukan hukum di Indonesia.

Pengertiannya yang dahulu undang-undang Nomor 17 tahun 1964 adalah merupakan pidana dan setelah dikeluarkan undang-undang Nomor. 1 Tahun 1971 yang mencabut peraturan undang-undang Nomor 17 tahun 1964 tidak merupakan pidana lagi.

Dari perihal tersebut Cek dan Bilyet Giro (BG) merupakan suatu alat pembayaran, namun kegagalan dalam pembayaran utang yang dimulai dalam perjanjian dapat dikategorikan sebagai wanprestasi atau gagal bayar dan bukan karena keadaaan memaksa (overmacht). Menurut Pasal 1234 KUHPer bahwa prestasi tersebut terdiri tiga pengertian, yaitu :

a. Prestasi untuk menyerahkan sesuatu yang artinya prestasi ini diatur dalam Pasal 1237 KUHPerdata;

b. Prestasi dalam melakukan berbuat sesuatu, hal ini terdapat dalam Pasal 1239 KUHPerdata;

c. Prestasi pada tidak berbuat atau tidak melakukan sesuatu, yang hal ini diatur dalam Pasal 1239 KUHPer.

Bila melihat kasusnya Sudianti Ali dimana yang semula diawali perjanjian hutang terhadap Sukmawan Alia Kaliong yang seharusnya adalah ranah perdata yang dapat dilindungi Pada Pasal 1234 Kitab Undang-Undang Hukum Perdata (KUHPer) bahwa prestasi, dimana Ali hanya tidak mampu melaksanakan prestasinya, namun hal ini lembaga penyidik ataupun struktur menarik ke Pasal 378 KUHP.

Maka untuk itu Negara harus dengan tegas menyatakan di dalam undangundang nomor 1 tahun 1971 apabila didahului adanaya perjanjian hutang-pitang dan bila terjadi wanprestasi ataupun sesoarang gagal dalam menujukkan prestasinya harus didahului penyelesaian secara damai mulai dari tingkat penyidik, Penuntut umum dan pengadilan untuk pencegahan timbulnya permusuhan dan kericuhan dalam masyarakat dan bila perdamain tidak tercapai dan harus terpaksa ke ranah pengadilan dapatlah dibawa ke ranah keperdaataan

3. Budaya Hukum/ kultur Hukum : Menurut Lawrence M. Friedman Yang dikutip oleh Soerjono Soekanto ${ }^{9}$ mengenai budaya hukum atau kultur hukum:

"The legal culture, system their beliefs, values, ideas and expectation." (kultur hukum merupakan sikap manusia terhadap hukum, sistem hukum kepercayaan, nilai, pemikiran, serta harapannya). "Legal culture refers, then, to those ports of general culture-customs, opinions, ways of doing and thinking that bend social forces to ward from the law and in particular ways" (kultur hukum adalah suasana pemikiran sosial dan kekuatan sosial yang menentukan bagaimana hukum digunakan,dan atau

\footnotetext{
${ }^{9}$ Soerjono Soekanto, Op Cit,; hlm 9
} 
disalahgunakan ). Dan Freidman juga menyatakan bahwa budaya hukum juga merupakan sebagai bensinnya motor keadilan dan bahwa budaya hukum adalah total keseluruhan faktor yang menentukan bagaimana sistem hukum tersebut memperoleh tempat yang logis dalam kerangka budaya yang dimilikin oleh masyarakat umum. ${ }^{10}$

Kultur hukum atau budaya hukum diibaratkan sebagai benda yang termasuk pada kategori siapa saja atau apa saja yang menghidupkan dan mematikan mesin penggerak itu serta memutuskan bagaimana mesin dapat digunakan yang berarti, kultur hukum atau budaya hukum termasuk pada kepercayaan atau keyakinan, opini, ide, kebiasaan, sikap cara bertindak dan cara berpikir mulai dari penegak hukum ataupun dari masyarakat tentang hukum dan berbagai petunjuk yang berkaitan dengan hukum. ${ }^{11}$

Bila melihat kasus tersebut diatas dimana pemberian cek/giro diawalai adanya perjanjian peminjaman dana, dimana yang seharusnya ranah perdata akan tetapi digiring ke ranah pidana dengan Pasal 378 KUHP oleh penyidik.

Masyarakat merupakan subjek dan juga objek hukum yang akan semakin berkembang dimana ketidak percayaan masyarakat terhadap hukum., yang berimbas pada anggapan ketidak profesionalisme atau ketidak mampuan dalam menganalisa dan juga penegak hukum akan bahan pertanyaan oleh masyarakat luas. Jika masih berlanjutan seperti putusan di atas terus menerus atau sering dibuat dilakukan pembiaran oleh institusi penegak hukum atau pengadilan sendiri dimana di intenal masing-masing tidak melakukan pengawasan dan sepertinya menunggu adanya laporan dari masyarakat dimana yang terjadi adalah masyarakat akan semakin tidak percaya hukum, tingkat kepercayaan dalam masyarakat terhadap hukum akan semakin menjadi buruk terhadap hukum begitu juga dengan terhadap pelakasana penegakan hukumnya.

\footnotetext{
${ }^{10}$ Kurniawan Tri Wibowo, Op Cit ; hlm 38

${ }^{11}$ Achmad Ali , Keterpurukan Hukum Di Indonesia, Jakarta:2002 Ghalia Indonesia,, hal. 9 


\section{Kesimpulan :}

Bahwa Peraturan undang-undang No. 17 Tahun 1964 tersebut menimbulkan keengganan masyarakat menggunakan cek atau Bilyet giro dalam sistem lalu-lintas pemabyaran dalam berbisnis, maka pemerintah mencabut undang-undang tersebut dengan mengeluarkan peraturan undang-undang Nomor. 1 Tahun 1971 mengenai pencabutan larangan penarikan Cek kosong, Artinya semula merupakan pidana dan setalah terbitnya UU nomor 1 Tahun 1971 menjadi bukan pidana lagi (Kriminalisasi menjadi Dekriminalisasi);

\section{Saran :}

Melihat teori dari Lawrence M.Fridman bahwa struktur hukum seperti mulai Kepolisian, Jaksa Penuntun Umum, Hakim pengadilan dan Lembaga pemasyarakatan harus dapat bersinergi dan profesiaonal dalam menangani suatu

perkara menganai penggunaa Cek dan Giro, dimana tidak harus memaksakan ditarik ke ranah pidana. Ketiga srtiktur tersebut harus dibekali ilmu pengetahuan atau bisa menjadi pengayoman masyarakat, semua kepala lemabaga struktur diatas harus dapat mempertanggung jawabkan perbutan stafnya apabila salah mnerapkan pertauranperaturan yang sudah menjadi undang-undang. 


\section{Daftar Pustaka}

\section{Buku}

Ali , Achmad. 2002, Keterpurukan Hukum Di Indonesia, Ghalia Indonesia, Jakarta Hasyim, Farida. 2009, Hukum Dagang, Sinar Grafika, Lampung

Lawrence, M.Friedman, Sistem Hukum Persepektif IImu Sosial, Diterjemahkan oleh M.Khozim, Nusamedia 2011

Kusumaatmadja, Mochtar. 1995 Hukum, Masyarakat, dan Pembinaan Hukum Nasional, Bina Cipta, Bandung

Tim Redaksi BIP, Bhuana IImu Pelopor, IKAPI: 246?GKI/04

Triwibowo, Kurniawan. 2020, Hukum dan Keadilan-Peradilan yang tidak Kunjung Adil, Papas Sinar Sinanti, Jakarta

\section{Perundang-undangan}

Undang-undang Republik Indonesia nomor 1 Tahun 1971 tentang pencabutan Larangan penarikan Cek kosong nomor 17 Tahun 1964

Undang-undang Republik Indonesia nomor 17 Tahun 1964 tentang larangan penarikan cek kosong 